\title{
Yeni Medyanın Kültürel Miras Konulu Uygulamaları
}

\author{
ÜFTADE MUŞKARA*
}

\begin{abstract}
ÖZ
Yeni medya, kültürel miras alanında kısmen yeni bir ortamdır. Yeni medya genellikle dijital ve teknolojik tabanlı bir alternatif olarak kabul edilir. Yeni medya kavramının kültürel miras alanında daha iyi anlaşılması kültürel miras unsurlarının korunması, canlandırılması ve yönetimi açısından yeni ve dinamik olanaklar yaratır. Kültürel miras unsurları yeni medyanın öznesi olduğunda, yeni medya uygulamalarının geliştirilmesinde her iki alanda da uzmanların ortak çalışması gereklidir. Yeni medya uygulamaları arkeoloji bilimi ile koruma ve onarım ilkelerine göre yapılandırılmazsa, kültür mirasına konu olan eserler kolaylıkla manipüle edilebilir ve kullanıcılar yanlış yönlendirilebilir. Çalışmada, kültürel miras alanında uygun ve etkin yeni medya uygulamalarının geliştirilebilmesine yönelik önerilerin sunulması amacıyla yeni medya kavramı ile arkeolojik sit alanlarında ve yapılarda son dönemin popüler uygulamaları incelenmiştir. Yeni medya uygulamalarının amacı, öznesi olan kültürel miras ve kullanıcı üzerindeki etkisi olarak üç bileşen belirlenmiş ve bu bileşenler bazında yeni medyanın kültürel miras alanındaki uygun kullanımı değerlendirilmiştir. Bunun yanı sıra, bugün bazı tanımlara göre eski medya ortamları olarak kabul edebileceğimiz analog medyalarının dijital değerlere dönüştürülerek melez metotlarla, kültürel miras alanında uygulanabileceği olasılığ belirtilmiştir.
\end{abstract}

Anahtar sözcükler: Yeni medya, dijital medya, kültürel miras, koruma ve onarım, arkeoloji, mimari miras

Yrd. Doç. Dr., Kocaeli Üniversitesi, Grafik Bölümü/KOCAELİ

E-posta: uftadem@gmail.com 
\ültürel miras, bir toplumun kimliği, kültürü ve tarihi ile ilgili ortak geç1 mişini anlatan maddi ve manevi değerlerin toplamıdır. Kentler ve tarihi dokular, anıtsal yapılar, arkeolojik alanlar ve dil, gelenek, dans, müzik, ritüeller gibi yaşayan ama somut olmayan değerler kültürel mirası oluşturur. Gelişen teknoloji ve iletişim sistemleriyle küreselleşmiş dünyanın sosyo-ekonomik yapısında kültürel mirasın korunması, kültür zenginliğinin/çeşitliliğinin gelecek nesillere aktarılması için önceliğe sahiptir.

Özellikle Türkiye'de, kültürel miras sadece geçmişin varlığını geleceğe taşıyan bir araç değil aynı zamanda güncel hayat içinde kalıntılar, anıtsal yap1lar, sit alanları ve geleneklerle yaşayan bir gerçektir. Bulunduğu coğrafyada somut olmayan kültürel miras ile birlikte arkeolojik, mimari ve tarihi miras o yörenin halkıyla beraber nesilden nesile aktarilarak bulunduğu toplumun kimliğini oluşturmakta ve devamlılığını sağlamaktadır. Benzer şekilde, sosyal beraberliğin ve bütünlüğün devamına önemli katkı yapmaktadır.

Son dönemde kültürel miras değerlerinin korunması alanında birçok yenilik ve gelişme yaşanmaktadır. Bunlardan biri, aynı zamanda sentez bir metot olan "yeni medya" uygulamalarıdır. Yeni medya kavramı ve kültürü sosyal ilişkiler, iletişim, reklam ve sanat gibi yaşantımızın her alanına biz çok farkına varamadan hızla girmiştir. Yeni medyanın kültürel miras alanında kullanımı da sağladığı teknolojik olanaklar açısından kolaylıkla benimsenmiş ve yayginlaşmıştır. Anlamlandırılması ise sonrasındaki süreçte gerçekleşmektedir. Yeni medya uygulamalarının analizini de bu noktadan bakarak yapmak gereklidir. Mevcut uygulamaların uygunluğunu, kültürel miras öğeleri ve kullanıcı açısından değerlendirerek arkeolojik ve mimari mirasın koruması ilkeleri doğrultusunda bir kapsam ve yöntem belirlemek gereklidir.

Çalışmanın amacı, yeni medya uygulamalarının kültürel miras alanında daha etkin kullanılabilmesi ve kullanıcıya doğru ulaşabilmesi için uygulamayı geliştiren uzmanlar ve kültürel miras ile ilgili tüm uzmanların ortak çalışmasının önemini vurgulamaktır. Bu bağlamda öncelikle "yeni medya" tan1$\mathrm{m} 1$ değerlendirilecektir. Yeni medyayı hedefe yönelik olarak kullanabilmek için yeni medyadan ne anladığımız irdelenecektir. Yeni medyanın ülkemizde farklı alanlardaki algılanı̧ı ve farklı alanlardaki uygulamalarından bahsedilecek ve genel anlamda dünyada kültürel miras alanında yeni medya kavramı çerçevesinde yeni medya uygulamaları anlatılacaktır. Öznesi kültürel miras olan yeni medya uygulamalarının, geleneksel yöntemlere göre tercih edilir olmasını sağlayacak bileşenler belirlenecek ve yeni medyanın kültürel mirasın korunması alanındaki kullanımı için öneriler sunulacaktır. 


\section{Yeni Medya}

Yeni medya daha çok dijital ortamda güncel teknolojinin kullanımıyla ilintili olarak algilanmaktadır. Yeni medyadan söz edilirken internet, harici bellek, bilgisayar oyunları, 3 boyutlu yazıcılar ve sanal gerçeklik ilk akla gelen ortamlardır. Teknolojinin son yirmi yılda geçirdiği hızlı gelişim, yeni medya kuramcılarının yeni olarak tanımladığı araçların bile güncelliğini kaybetmesine neden olmakta ve "yeni” olma tanımını tekrar gözden geçirmeyi gerektirmektedir. Yeni medya ile ilgili ilk sistematik teoriyi oluşturan Manovich’in sıraladığı yeni medya ortamlarından CD-ROM bugün yerini daha gelişmiş araçlara bırakmıştır (2001: 19). Manovich yeni medyayı daha çok bilgisayar teknolojisi ve bilişim sistemleriyle paralel olarak algilayarak “yeni” yi bu bağlamda sorgulamaktadır. 14. yüzyılda matbaa ve 19. yüzyılda fotoğrafin toplum ve kültür üzerindeki devrimsel etkisi ile yeni medyanın modern toplumdaki etkisini benzeştirir. 20. yüzyılın sonundan itibaren kültürün bilgisayar tabanlı üretim, dağıtım ve iletişime evrildiği "yeni medya" devrinin ortasında olduğumuzdan bahsetmektedir.

Yazı, ses ve görüntünün bilgisayar ortamında işlenebilir numerik veriye dönüşmesinin yeni medyayı oluşturduğunu söyleyerek yeni medya ile ilgili temel prensip oluşturmaktadır: numerik temsil, modülerlik, öz devinim, değişkenlik ve kültürel kod (Manovich 2001: 20).

İlk 4 prensip yeni medyanın somut özelliklerini tanımlarken, kültürel kod prensibi medyanın bilgisayar düzlemine geçmesinin en önemli sonucu olarak değerlendirilmektedir (Manovich 2001: 45). Manovich'in yeni medyası olan bilgisayar ortamında objelerin kültürel katmanı ve bilgisayar katmanı bulunmaktadır. Ona göre yeni medya bilgisayarda yaratıldığı, bilgisayar yoluyla yayıldığı ve bilgisayarda depolandığı için bilişim dili ya da bilişim mantığı geleneksel medya mantığını büyük ölçüde etkilemiştir. Manovich, yeni medyanın ne olduğunu anlamak için bilgisayar bilimlerine yönelmek gerektiğini ve bu şekilde programlanabilir hale gelen medyayı karakterize edebilecek yeni bir terminoloji oluşturmanın mümkün olacağını savunmaktadır (2001: 48). Tanımladığ1 5 prensip de bu düşünceye uygun olarak geliştirilmiştir.

Yeni medyayı anlamaya çalışırken "medya" ile neyi tanımladı̆̆ımız da önem kazanmaktadır. Medyumun kökeni orta kısım anlamındaki Latince medius kelimesine dayanmaktadır (Courtney 1986: 539). 50 yıldan fazla bir zamandır ise medya tek bir kolektif terim olarak kullanılmaktadır (Williams 1976: 169). Lister, Dovey, Giddings, Grant ve Kelly medya denildiğinde iletişim medyasının düşünüldügünü ve basılı medya, fotoğraf, reklam, sinema, televizyon ve radyo gibi sektörlerin akla geldiğini; terimin aynı zamanda bu 
sektördeki kurumların kültürel ve maddi ürünlerini de tanımladığını söylemektedir (2009: 10). Medya, Türk Dil Kurumu Türkçe sözlüğünde de iletişim ortamı olarak açıklanmaktadır (Türk Dil Kurumu, Erişim tarihi: 9 Ekim 2017, http:/www.tdk.gov.tr/index.php?option=com_bts.).

Yeni medyanın kavram olarak sorgulandığ kaygan bir düzlemde yeni medya tanımının bu kadar yaygın olarak kullanılmasıyla ilgili Lister, Dovey, Giddings, Grant ve Kelly 3 öneri sunmaktadır: 1. yeni medya, geçmişi ve geleceği olan tarihsel bir süreç olarak algılanır; 2. "yeni" konseptinin kendisi ütopik ve olumlu bir ideolojik gücü anlatır; 3. yeni, yeni medyanın dijital ya da interaktif gibi daha teknik tanımlara indirgenmesine engel olur (2009: 10).

Yeni medya, medya yapım, dağıtım ve kullanımdaki büyük değişikliğin tümünü kapsayacak bir anlama karşılık gelmektedir. Bu bağlamda, Lister, Dovey, Giddings, Grant ve Kelly yeni medyanın karakteristik özelliklerini dijital, interaktif, üst metin, sanal ortam, ağ tabanı ve simülasyon olarak belirtmektedir (2009: 13). Bu özelliklerin hepsi bir yeni medya objesinde aynı anda ya da belli derecelerde kullanilabilmektedir.

Tarihsel süreçte değerlendirdiğimizde, bazı teorisyenler yeni medyayı, medyanın tüm zamanlar içindeki gelişiminin kümülatif toplamı olarak açıklamaktadır.

Weibel, görüntü prodüksiyonu ve iletimi teknolojilerinin gelişimi için 8 aşamalı 160 yıllık tarihsel bir model önermiştir (1996: 338). Bu yaklaşımla ilgili en büyük problem medya tarihinin çizgisel bir gelişim süreci olarak değerlendirilmesi ve aşamaların birbirleriyle ilişkilerinin çok net ortaya konmaması olarak belirtilebilir. Poster sorunu Foucault'ın soybilimi (jenealoji) ile cevaplamaya çalışmıştır (1999: 12). Buna göre süreç kümülatif gelişimlerin çizgisel düzlemde oluşan sonucu olarak değil, ağlar, kümeler, sınırlar, alanlar ve kesişmeler bağlamında değerlendirilebilir. Lister, Dovey, Giddings, Grant ve Kelly özdevinim teorisinin (automata) başlangıcı olan MS 1. yüzyıldan yapay yaşama uzanan süreci açıklamak için felsefe sistemleri, hesap makinas1, fotoğraf, dokuma sektörü, coğrafi keşifler ve kolonileşme gibi gelişmeleri birbiriyle ilişkili olarak kapsayan farklı bir model önermektedir (2009: 59).

Bazı araştırmacılar ise yeni medyaya yaklaşımımızın eskisinin etkisinde kalması, kültürel bariyerlerimiz ve buna bağlı alışkanlıklarımız nedeniyle yeni medyanın ne olduğunu tam tanımlayamadığımızı ve işlevsel kullanamadığımizı savunmaktadır (Youngblood 1999: 48; Holzmann 1997: 15).

Manaovich'in bahsettiği yeni medyanın interaktif karakteristiği ise özellikle “izleyici” tanımı bağlamında medyanın tüketimini değişmiştir. “İzleyici” artık 
"kullanıcıya” ve "tüketici” de “üretici”ye dönüşmüştür. Özellikle televizyonun insanın yaşayış biçimine etkisiyle oluşan "edilgen izleyici” nin bugün hızla şekil değiştirmekte olduğunu gözlemlenir.

Sanayi devrimi ve pazar ekonomisi, büyük aile yapısını parçalayarak bireysel yaşantıyı destekleyen bir sistem oluşturmuştur (Lister ve Dovey, Giddings, Grant, Kelly 2009: 75). Aynı zamanda kültür ürünlerinin kendisi de kapitalist sistemin öznesi haline gelmiştir. Poster da, "eski” ve İkinci Medya Çağ1 olarak nitelendirdiği "yeni” arasındaki en büyük farkın eskisinde edilgen, yenisinde ise etken kullanıcı özelliği olduğunu söylemektedir (1990: 33). Büyük kuruluşların televizyon ve basılı yayın aracılığıyla geniş kitleleri yönlendirdiğini, yeni medyanın meyvesi olan internetin ise alternatif bir kamusal alan yarattığını belirtmektedir.

Kitle iletişim kuramları bağlamında, iki ünlü medya teorisyeni McLuhan ve Williams'in medya ve teknolojiyi farklı filtrelerden geçirerek nasıl irdelediklerine değinmek gerekir. Her ikisi de en etkili eserlerini 60'lı ve 70'li yıllarda yazmışlardır. McLuhan kışkırtıcı ve iddialı kişiliği ile 60 'lı yıllarda popüler bir rol kazanmış ve düşünceleri Baudrillard, Virilio, Poster, Kroker, De Kerckhove gibi yeni medya teorisyenleri tarafından benimsenmiş ve geliştirilmiştir. McLuhan Gutenberg Galaksisi (2014), Understanding Media: The Extensions of Man (1964), The Medium is The Massage (1967) ve War and Peace in Global Village (1968) gibi önemli kitaplarını kişisel bilgisayarların iletişim ve medya prodüksiyonunda kullanılmasından yaklaşık 20 yıl öncesinde yazmıştır. 500 yıllık basılı medya kültüründen elektronik medyaya dönüşümü radyo ve televizyon üzerinden tanımlamaktadır. Bazı araştırmacılar, fikirlerini 90'lı yıllarda yeni medya alanına uyarlandıklarında McLuhan'ın önsezilerinin sıra dışı biçimde güçlü olduğunu düşünmektedir.

McLuhan 4 tip medya kültürü başlı̆̆ını oluşturmuştur (1994): 1. Sözlü iletişimin ilkel kültürü 2. Sözlü iletişimle bir arada yaşayan fonetik alfabe ve el yazısı kullanan okur-yazar kültürü 3. Kitlesel üretim ve mekanik baskı çağı ve 4. Elektronik medya: radyo, televizyon ve bilgisayarların kültürü.

İlkel insan, modern Batı'nın yaratabileceğinden çok daha acımasız kozmik bir makinada yaşamaktadır ve işitme duyusu duyarlılık kazanmıştır $(\mathrm{McLu}-$ han 1994: 156). Okuryazar kültürü, 1. kültüre göre daha gelişmiş bir durum olarak görmektedir. Gözün uzantısı olarak alfabe ve yazıyla ve sonraki aşamalarda saatle, zamanın görsel ve tekdüze bölümlendirilmesinin mümkün hale geldiğini söylemiştir. Gutenberg Galaksisi’nde tipografik insanın oluşumu ile anlattığ1 baskı çağ1 McLuhan için hikayedeki gerçek kötü karakter olarak tanımlanabilir. Baskı makinası ile kültür, görseller etkisiyle hipnotize edilir- 
ken daha önce uyum içinde olan duyuların karşılıklı etkileşimi sona ermiştir (2014: 17-18). McLuhan ve benzer görüşte olan araştırmacilar elektronik medya ve devamındaki yeni medya ile insanın sözlü kültürdeki şartlarını geri kazandıklarını savunmaktadır. Duyguların uyumu telgraf, televizyon, radyo ve bilgisayar ile tekrar sağlanmaktadır. Lister, Dovey, Giddings, Grant ve Kelly göre McLuhan televizyonun dokunsal bir ortam olduğunu anlatmak için büyük çaba sarf etmektedir (2009: 82). Buna bağlı olarak da yeni tür bir ilkelliğin oluştuğu Küresel Köy kavramı pozitif bir tanımlama biçiminde karşımıza çıkmaktadır. McLuhan, bireyselleşen toplumun, elektronik medya araçları ile tekrar birbirine bağlandığını, iletişime ve etkileşime geçtiğini savunmuştur. $\mathrm{Bu}$ görüş, günümüzde yeni medya çalışmalarında da karşılı̆̆ını bulmaktadir.

McLuhan medyanın teknolojik boyutu üzerinde durur ve aslında teknoloji ve medya arasında bir fark olmadığını söylemektedir. "Teknoloji ve medya, insan duyularının bir uzantısıdır” düşüncesi bu görüşüne kaynak oluşturur. Medium is the Massage kitabında, tekerlek ayağın, kitap gözün, giysi tenin ve elektrik devresi ise insanın merkezi sinir sisteminin uzantısıdır bağlantısını kurmaktadır (1968: 142). McLuhan'a göre bunlar aynı zamanda birer medya aracıdır ve aracı neden ya da nasıl kullandığımız değil, aracın kendisi kültürel önem taşımaktadır.

Williams’a göre teknoloji insanın yaptığı ya da yapacağı öngörülen ve istenen işlere yardımcı olması için şekillenmiş ve geliştirilmiştir (1974: 129). Williams, McLuhan'ın yeni teknolojilerin insanlığın fiziksel işlevlerini radikal olarak değiştirdiği görüşünü eleştirmektedir. Ona göre yeni teknolojiler var olan ve belirli sosyal grupların önemli ya da gerekli gördüğü uygulamaları daha ileriye taşımaktadır (1974: 126-128).

McLuhan yeni teknolojilerin biyolojik ve psikolojik etmenlerle ortaya çıtktğını savunurken, Williams bunu sosyal dürtülere bağlamaktadır. McLuhan medyayı, teknolojinin bir türü olarak görürken, Williams medya kavramını tartışmalı bulmakta ve medya ve teknolojinin ilintili kullanımına şüphe ile yaklaşmaktadır.

Yeni medyaya ilişkin farklı görüşleri ve kuramları değerlendirdiğimizde; yeni medyanın en belirleyici özelliklerini, kültürel ya da analog formda kodlanan verilerin dijital ortamda oluşturulması, saklanması, yayımlanması ve kullanıcının bu ortamdaki interaktif yapısı olarak nitelendirilebilir. Ancak, "yeni medya” olarak tanımladığımız ortamda kullanılan araçlarının teknolojik gelişmelerle bağlantılı olarak her zaman geliştirilebileceğini düşündüğümüzde yeni medya uygulamalarının sadece belli bir dönem için yeni olmasından söz 
etmek mümkündür. Diğer yandan çağdaş medya araçlarının analog ya da dijital ortamdaki uygulamalarında görülen bir yenilik de onları bu alan için "yeni medya" kılmaktadir.

\section{Türkiye'de Yeni Medya Yaklaşımları}

Yeni medya araçları ülkemizde özellikle iletişim, reklam sektörü, kültür ve sanat bağlamında sorgulanır ve uygulamaları daha çok bu alanlarda gözlemlenmektedir.

Aktaş 2007 yılında yayımlanan çalışmasında geleneksel medya ve yeni medya arasındaki farklılıkları Kanal, Kontrol, İletim, İçerik, Kapsama Alanı, Toplumsal Kontrol, Zaman ve Organizasyon Yapısı başlıkları altında incelemiş ve her iki tür medyanın bu başlıklar bakımından radikal bir şekilde ayrıldıkları sonucuna varmıştır (10-11). Yeni medyanın temel özelliklerini de sayısallaşma, farklı medyaların yöneşmesi, etkileşim, internet'in kitle iletişiminden ayrılması, kullanıcının içeriği etkilemedeki rolü, toplumsal kontrolün azalması ve asenkron iletişim olarak belirlemiştir. Aktaş, yöneşmeyi telekomünikasyon, veri iletişiminin ve kitle iletişiminin bütünleşerek tek bir ortama dönmesi olarak açıklar. Yöneşmenin temel prensibi ise verinin numerik olarak kaydedilmesidir. Böylelikle yeni medyanın dijital olmasının altı çizilmiş ve bunun fiziksel etkileri ile ilgili özellikler belirlenmiştir.

Kaplan ve Ertürk dijital çağda iktidarın teknolojiyi ideolojik bir araç olarak kullanmasını ve bireylerin direniş için yine teknolojiyi ve dijital ortamı seçmeleri konusunu incelemişlerdir (2012). Frankfurt Ekolü'nün, medyanın izleyiciyi kitlesel olarak etkileme gücü ve bilgiyi ideolojik süzgeçten geçirerek izleyiciye sunduğu görüşüne uygun olarak medya ideolojisinin çıkar gruplar1 ideolojisi ile özdeşleşmesi olduğunu söylemektedirler. Medyanın ideolojik propaganda aracı olarak kullanılmasıly kurgulanmıs gerçekliğin gerçeğin yerini aldığını belirtirler. Araştırmacılar, çağdaş medya araçlarının özellikle teknolojik özelliklerinin önemine vurgu yaparken dijital çağ olarak adlandırdıkları güncel medya araçlarından sosyal medyanın bireyin ideolojik savunması açısından önemini anlatmışlardır (Kaplan ve Ertürk 2012: 9-11).

Akyazı dijital katılımcı sözlüklerde oluşan yeni topluluklar ve bu ortamlarda kadına ve erkeğe yönelik nefret söylemlerini araştırmıştır (2014). Öncelikle yeni kavramını sorgulayan Akyurt, özellikle iletişim teknolojilerinin gelişim hızı dikkate alındığında yeni sıfatı üzerinden kurulacak olan retoriğin, söz konusu teknolojilerin toplumsal iletişim süreçlerine etkilerinin gereği gibi değerlendirilmesine engel olacağını savunmaktadır (Akyazı 2014: 184). Bili- 
şim bilimi çerçevesinde yeni medya kavramını yeni teknolojiler ile doğrudan bir bağlantı kurmadan, kitle iletişim ortamının sunduğu olanaklar açısından etkileşimin artması olarak tanımlamıştır (Akyazı 2014: 186).

Yaylagül ise "Kitle İletişim Kuramları" kitabında İletişime Teknolojik Yaklaşımlar alt başlığında Innis, Mcluhan ve Katz'dan söz eder (2010: 68). Innis medyaya ilişkin belirgin bir biçimde Kuzey Amerika bakış açısından oluşturduğu söylem ile tanınmıştır. Innis'in iletişim kuramı teknokratiktir. McLuhan'ı derinden etkilemiş ve böylelikle iletişim teorilerinde önde gelen bir figür olmaya devam etmiştir. Innis, teknolojiyi bağımsız değişken olarak kabul etmekte ve çağdaş teknolojinin iletişim araçlarını ve toplumların örgütleniş biçimini belirlediğini savunmaktadır.

Katz kitle iletişimi çalışmalarında etkin olan bir sosyologdur. Lazarsfeld ile birlikte yazdıkları Bireysel Etki: Kitle İletişiminin Işleyişinde Insanların Rolü (Personal Influence: The Part Played by People in the Flow of Mass Communications, 1955) başliklı kitapla kitle iletişim alanında yaygın bir etkiye sahip olmuştur. Katz duruma farklı bir açıdan bakarak medyanın insan üzerindeki etkisine değil insanın medyayı kullanışs şekline dayalı "Kullanımlar ve Doyumlar” yaklaşımının temelini oluşturmuştur (Yaylagül 2010: 70). Katz'a göre insanların toplumsal ve psikolojik ihtiyaçları bulunmaktadır. Medya ile ilişkilerini bu ihtiyaçlar belirler ve bunların bazısını medyayı kullanarak gidermektedir. Ancak medya ile ilişkilerinde beklenmedik ve istenmeyen sonuçlar da ortaya çıkabilir. "Kullanımlar ve Doyumlar" yaklaşımında insan ve medya arasında işlevsel bir ilişki kurulduğu kabul edilmektedir.

Şahin gelişen teknoloji ve dijital devrim bağlamında yeni medya sanatını sorgulamaktadır (2015). Özellikle sanal gerçekliğin bir sanat ortamı olarak kullanıldığ ve işin bir parçası olmasına giden sanattaki dönüşümü aktarmaktadır (Şahin 2015: 43-48). Bu dönüşümü, teknoloji ve özellikle dijital ortamda yeni medya araçlarının insan algısını belirsizleştirmesi ve "gerçeklik algısının" bulanıklaştırması olarak yorumlamaktadır. Sonuç olarak, teknolojik bağımlılı̆̆ın artması ve medyanın sayısallaşması ile sanatın söyleminin yeniden şekillendiğini, yakın gelecekte teknolojisinin bir sanat ortamı olarak kullanılmasının devam etmesiyle sanat eseri ve izleyici arasındaki ilişkinin dönüşümünün devam edeceğini söylemektedir (Şahin 2015: 48).

Odabaş ise yeni medya ve sanat ilişkisini sosyolojik bakış açısı ve kapitalizm ile ilişkisi yönünde değerlendirmektedir (Odabaş 2016). Kendi kültürünü oluşturan dijital devrimin geleneksel plastik sanatlar alanındaki uygulaması olan karışık teknikten bahsetmektedir. Odabaş yenileşmeleri süreklilik kav- 
ramı üzerinden çözümlemektedir. Ona göre bu yenileşmeler, daha önceki dönemlerde birbirini takip eden küçük adımlar olarak gerçekleşirken, 21. yüzyılda "sıçrama" olarak var olmuştur (2016: 464). Yazar, yeni medya platformunu bugün özellikle sanat alanında modernitenin çözmeye çalıştığı ama tam açıklayamadığı ve sonucunda kendisinin de gelenekselleştiği yeni bir dil arayışında kopuş noktasında olunduğunu düşünmektedir. Yeni medya ortamı ile değişen dil ve mekan algısının sanatlar arası sınırların kalkmasını sağlamış olmasından bahsederek karışık tekniği; dijital ortamda üretilen görselin, birden çok grafik ve resim işleme programından geçerek sonunda geleneksel ya da analog olan tuvale aktarılması ve yine geleneksel yöntemlerle işlenerek tamamlanması olarak tanımlamaktadır.

\section{Kültürel Miras Alanında Yeni Medya Uygulamaları}

Yeni medya uygulamalarının, kültürel mirasın korunmasında ve kültürel değerlerin görsel, işitsel ve yazılı olarak sergilenmesinin yanı sıra bunların sanal-gerçek platformda izleyiciye ve araştırmacıya ulaştırılması için günümüz teknolojilerinin sağladığı olanaklar göz önüne alındığında oldukça büyük bir etkisi olmaktadır.

İnsanoğlu binlerce yıldır bir şeyleri görselleştiriyor, resmediyor olsa da dijital görüntünün tarihi ancak on yıllarla ölçülebilmektedir. Dijital görüntünün bilim, sanat ve tasarım üzerinde yarattığı etki ve ulaştığı çeşitlilik ise bu kısa tarih göz önüne alındığında oldukça büyük ve şaşırtıcı ölçüde olmuştur (Wands 2006: 28-30). Kültürel alanda yeni medya söz konusu olduğunda genel olarak, dijital fotoğraf, dijital video, dijital görüntü ve resim işleme programları, video mapping, veri tabanlı uygulamalar, web tabanl1-internet uygulamaları ve birçok alt koldan oluşan bir yöntemler bütününden bahsetmek mümkündür.

Son yıllarda dünyada ve ülkemizde yeni medyanın kültürel miras alanındaki uygulamalarına ilişkin çalı̧̧maların sayısında önemli artış gözlemlenmektedir. Daha önce de belirtildiği gibi yeni medyanın gelişim hızı diğer alanlarda olduğu gibi kültürel miras alanında da uygulamaların bilimsel ve ilkesel kriterleri daha belirlenemeden yeni medya araçlarının kullanılmaya başlamasına neden olmuştur. Önümüzdeki süreç, yeni medyanın ve kültürel miras alanında kullanılan uygulamaların bileşenlerinin analizi ve değerlendirilmesidir.

$\mathrm{Bu}$ anlamda kültürel mirasın yeni medya kullanılarak korunması ile ilgili New Heritage: New Media and Cultural Heritage başlıklı kapsamlı çalışmanın giriş bölümünde, Kalay dijital ya da yeni medya olarak tanımladığı 
alanı ve bunun koruma bilimindeki önemi anlatmaktadır (2008: 1-10). Teknoloji tabanli yeni bir alternatif olarak yeni medyayı tanitırken yeni medyaya bilimsel ve teknik akıllı vurgulayan rasyonalite içinde teknokratik açıdan yaklaşmaktadır. Bu bağlamda bilginin biçimlendirilmesinde teknik yeterliliği olan uzmanların ve kurumların yeni medyayı, tehdit altında ya da yok olmuş kültürel miras unsurlarının yeniden canlandırılması için bilgisayar destekli modelleme ve görselleştirme yeterliliğine ilişkin olarak sahiplendiklerini söylemektedir. Kalay, yeni teknolojilerin modern koruma yöntemlerini durağan konumdan ileriye taşıyacak potansiyeli olduğunu belirtirken yeni medyanın sağladığ mektedir: Yeni medyanın kültürel miras alanındaki uygun kullanımı nasıl olmalıdır ve yeni medyanın koruma amacında olduğu kültürel miras üzerindeki etkisi nedir? Bu sorular dışında yeni medyanın kültürel miras alanındaki kullanımının üçüncü bir bileşen olarak kullanıcı üzerindeki etkisi de mutlaka değerlendirilmelidir.

Kalay, yeniden canlandırma, veri yönetimi ve yayılımı başlıklarında Manovich'in yeni medya için tanımladığ 5 karakteristiğin kültürel miras alanına özgü anlamlar kazandığını söylemektedir (2008: 3).

Dijital ortamda veri yönetimi, özellikle mimari yapıların yeniden canlandırılmasında avantaj sağlamaktadır (Kalay 2008: 5). Arkeologlar, mimari onarımda çoğu durumda çelişkili kaynaklara başvurmak durumunda kalırlar. Bunun yanı sıra yapılar, zaman içinde kullanım amacında ya da şeklinde değişiklik geçirmiş olabilirler. Tüm bu farklı veriler, bilgisayar aracılığı ile ayrı ancak yine de ilişkili olarak kaydedilebilir. Bu şekilde ulaşılan bilgiler ile benzer yapılar arasında bağlantıyı sağlamak da mümkün olabilir.

Kalay, dijital rekonstrüksiyonun maliyetinin göreceli olarak gerçeğine göre daha az olmasının farklı anlatı seçenekleri oluşturulması açısından da avantajlı olduğunu belirtmektedir (2008: 5). Ayrıca, dijital rekonstrüksiyonlarda farklı yorumların yan yana sergilenebileceğini, bu şekilde kullanıcıların farklı açıklamaları karşılaştırma şansı bulabileceklerini savunmaktadır. Ancak kültürel mirasa konu olan mekan ve nesnelerin dijital ortamda yeniden canlandırılması ve bu canlandırmanın uzaktaki kullanıcıya aktarılması, bilginin mekânsal ve zamansal boyutta değişikliğe uğramasına neden olabilir.

\section{Uygulama Örnekleri}

Yeni medyanın kültürel miras alanındaki kullanımına ilişkin bahsedilecek örnekler genel olarak farklı bakış açıları ve sistemler kullanılarak hazırlanan 
uygulamaların teknik özellikleri ile ilgili durumları temsil etmekte ve gelecekte alanı etkileyecek teknolojik yenilikler bakımından önemli basamakları oluşturmaktadır. Bunu yanı sıra bazı örnek uygulamalar çalışmanın amacını oluşturan, yeni medyanın kullanımında konuyla ilgili uzmanların işbirliği sağlanmadığında oluşabilecek sakıncaları göstermektedirler.

Yeni medya ve kültürel miras ilişkisini değerlendiren bazı çalışmalar belli gruplamalar oluşturma eğilimindedir. Liritzis, Al-Otabi, Volonakis ve Drivaliari kültürel miras çalışmalarında dijital teknolojinin arkeometri ya da arkeolojik bilimler bağlamında kullanımına ilişkin detaylı çalışmasında bu alandaki eğilimleri sanal arkeoloji, siber arkeoloji, siber arkeometri, sanal ortam, sanal gerçeklik, MMOW (massively multiplayer online virtual worlds, internet üzerinden binlerce kişinin aynı anda oynayabildiği oyun), zenginleştirilmiş gerçeklik, üç boyutlu arkeoloji, SfM (iki boyutlu görüntüden üç boyutlu görüntü oluşturma), oyunlaştırma, kültürel miras ya da müzelerin interaktif simülasyonu, uzaktan kumandalı uçaklar (drone) başlıkları altında açıklanmıştır (Liritzis ve Al-Otabi, Volonakis, Drivaliari 2009).

Themistocleous, sosyal medyada paylaşılan hava fotoğrafi ya da drone ile elde edilen verilerin kullanılarak özellikle tehdit altında bulunan kültürel miras alanlarının üç boyutlu modellemesi ve hava fotoğraflarının geometrik olarak arazi yapısına göre düzenlenebileceği bir sistem önermektedir (2016). Themistocleous, bu şekilde oluşturulan modellerin Google Earth'de görüntülenebileceğini ve sistemin ulaşılması güç bölgelerde bulunan özellikle taşınmaz kültür varlıkları kavramı ile doğrudan ilişkili olan askeri, dini ve endüstriyel mimari, mezar alanları, suyolları ve antik yerleşimlerin dijital yüzey modellemesi için kullanılabilineceğini belirtmektedir. Somut kültürel miras değerlerinin özellikle mimari yap1 ve yerleşimlerin dijital ortama aktarılmasına ilişkin olarak gelişmiş ve yaygın olarak kullanılan Google Earth uygulamasindan temellenen önemli bir uygulama önerisidir.

Yeni medyayla ilişkili farklı bir uygulama da Damiano ve Lombardo tarafından yapılmıştır. Damiano ve Lombardo tasarlayıp uygulamaya başladıkları Labyrinth 3D isimli sistemi teknik alt yapısı ve uygulama alanlarıyla ilişkili olarak tanıtmıştır (2016). Labyrinth 3D, kullanıcıların kültürel miras koleksiyonları içinde kendi kişisel yollarını yaratmalarına olanak veren ara yüzlerin yazılımını sağlayan anlamsal kodlama ile oluşturulmuştur. Uygulamada kullanıc1, bir set kapı ile çevrelenmiş bir sanat eserinin bulunduğu düğümsel bir alan içine yerleştirilmektedir (Resim 1). Her kapıda sanat eserinin ilişkili olduğu diğer eserlere ait kategorileri temsil etmektedir. Araştırmacilar, kültürel miras objelerini bu şekilde kullanıcı tarafından keşfedilmesi mantığı 
üzerine kurgulanan 3 boyutlu interaktif bir oyun olarak tasarlanan sistemin ileride eğitim faaliyetleri için de kullanılabileceğini savunmaktadır. Ancak, kullanıcının yaratılan bu sanal ortamda ekran üzerinden göreceği eserlerin gerçekliğini algılayabilmesi için farkındalığını kendisinin geliştirmesi beklenmektedir.

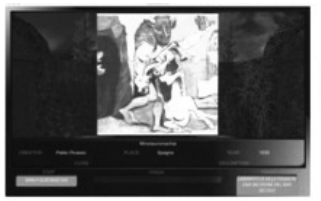

1. Categories from "Minotauromachia"

2. Crossroad for character

3. "Theseus killing the Minotaur"

4. Backtracking

5. Crossroad for object
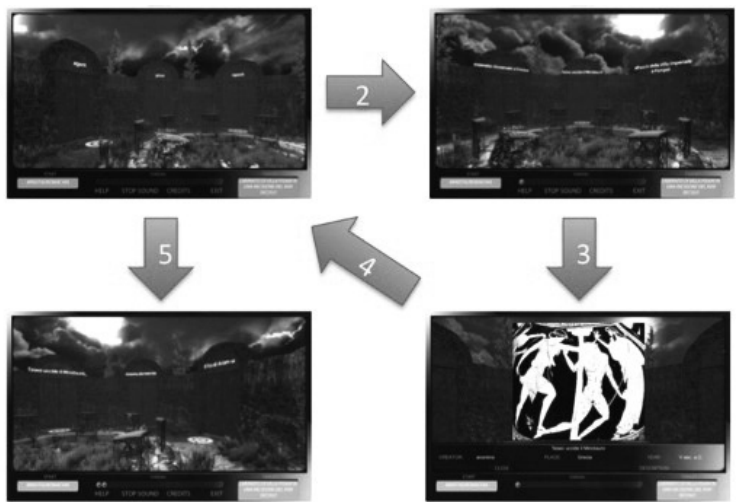

Resim 1 Labyrinth 3D uygulamasının ekran görüntüsü(Damiano ve Lombardo 2016: 247)

Khan ve Byl, zenginleştirilmiş gerçekçilik teknolojisinin somut olmayan kültürel miras örnekleri üzerine uygulanabilirliği konusunda çalı̧mıştır (2011). Sergilemelerde kullanılacak pedagojik içerikli uygulamaların, ziyaretçilerin müzelerde içinde geçirdikleri zamanın kalitesini arttıracağını savunan Khan ve Byl, bu şekildeki müdahalelerin somut olmayan kültürel mirası koruma, anlama ve yeniden canlandırma modellerinde henüz keşfedilmemiş yeni yöntemler oluşturulabileceğini anlatmaktadır.

Türkiye'de yeni medyanın kullanımı dijital canlandırma çalısmaları kapsamında başlamıştır. Yeni medyanın kültürel miras alanında en umut vadeden uygulamalarından biri olan zenginleştirilmiş gerçekliğin örneklerinden biri Bostancı tarafından geliştirilen Masaüstü Tarih isimli uygulamadır (Koyuncu ve Bostanc1 2007; Bostanc1 2011). Efes antik kentinin 3 boyutlu modelleri video görüntüler ile birleştirilmiş ve kenti gezen ziyaretçilerin eş zamanlı olarak belirli yapıların yeniden canlandırılmış hallerini görebilmeleri hedeflenmiştir (Resim 2-3). Ancak bu prototip, uygulamayı geliştiren uzmanın kendi alanıyla ilgili akademik bir çalışma olarak kalmış ve yaygınlaştırılamamıştır. 


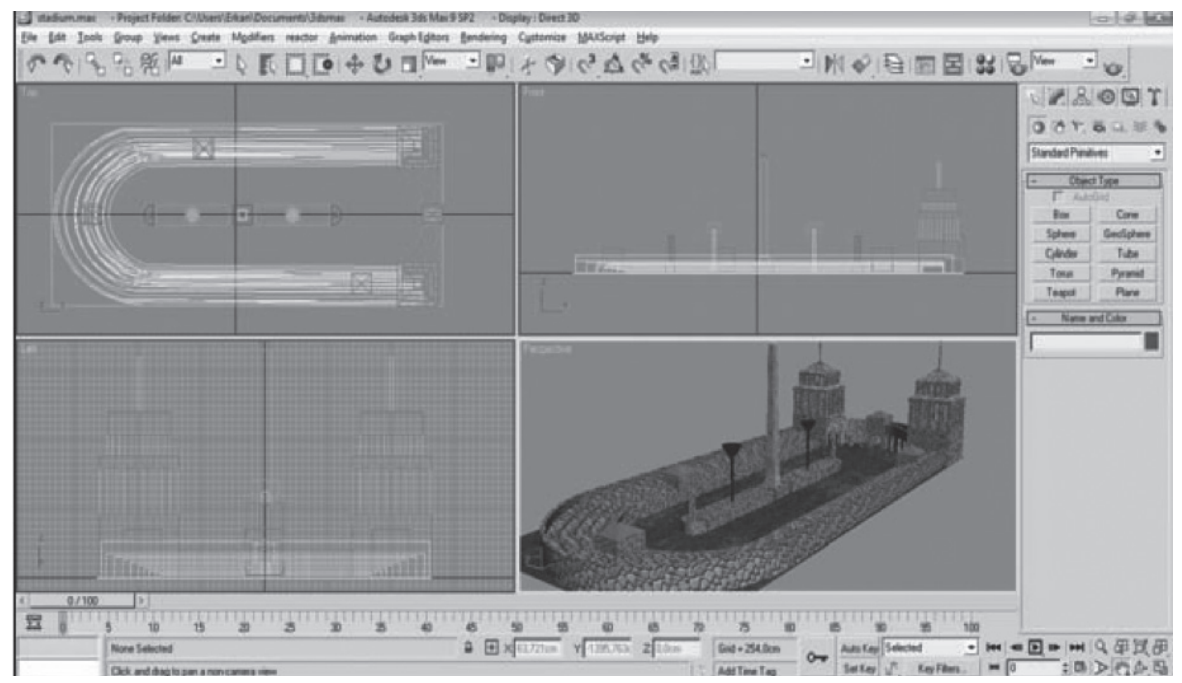

Resim 2 Efes antik kenti stadyum 3 boyutlu modelinin 3D Max programındaki görünümü (Bostancı 2011: 139)
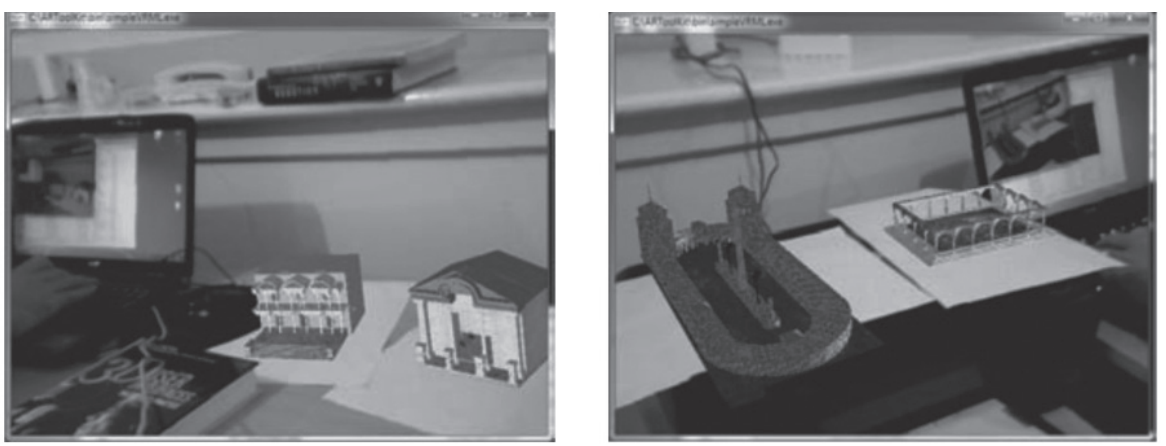

Resim 3 Efes antik kenti Celsus kütüphanesi, Hadrian tapınağı, stadyum ve Varius hamamının uygulama ile hazırlanan zenginleştirilmiş gerçeklik görüntüleri (Bostancı 2011: 139)

Özmen ve Balcısoy ise arkeolojik buluntuların bilgisayar ortamında 3 boyutlu modellemeler üzerinden ölçümünün alınmasına yönelik bir sistem tasarlamışlardır (Özmen ve Balcısoy 2006; Özmen ve Balcısoy 2008). CH Toolbox ismi verilen bu sistem arkeologların özellikle taşınabilir kültürel miras varlıkları olan pişmiş toprak vazolar ve heykellerin 4 boyutlu ölçümlerini almalarını sağlamaktadır (Resim 4-5). CH Toolbox uygulaması da hedef kitlesi olan arkeoloji alanında yaygınlaştırılamamıştır. Çünkü, kullanıcılara sağladığı yarar bağlamında kullanıcı olan arkeologların işbirliğinde hazırlanmadığı anlaşılmaktadır. 


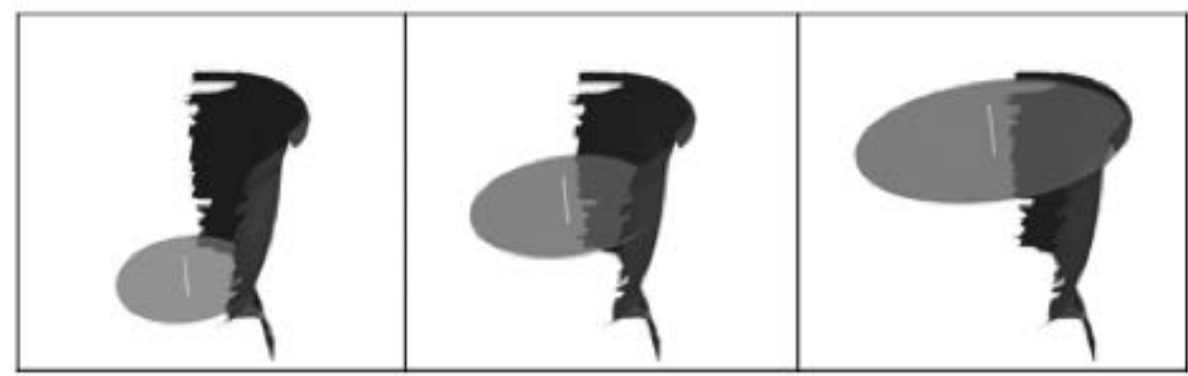

Resim 4 CH Toolbox uygulaması ile pişmiş toprak bir vazonun kaide, gövde ve ağız çaplarının sanal ortamda ölçümünün görüntüsü (Balcısoy ve Özmen 2008)

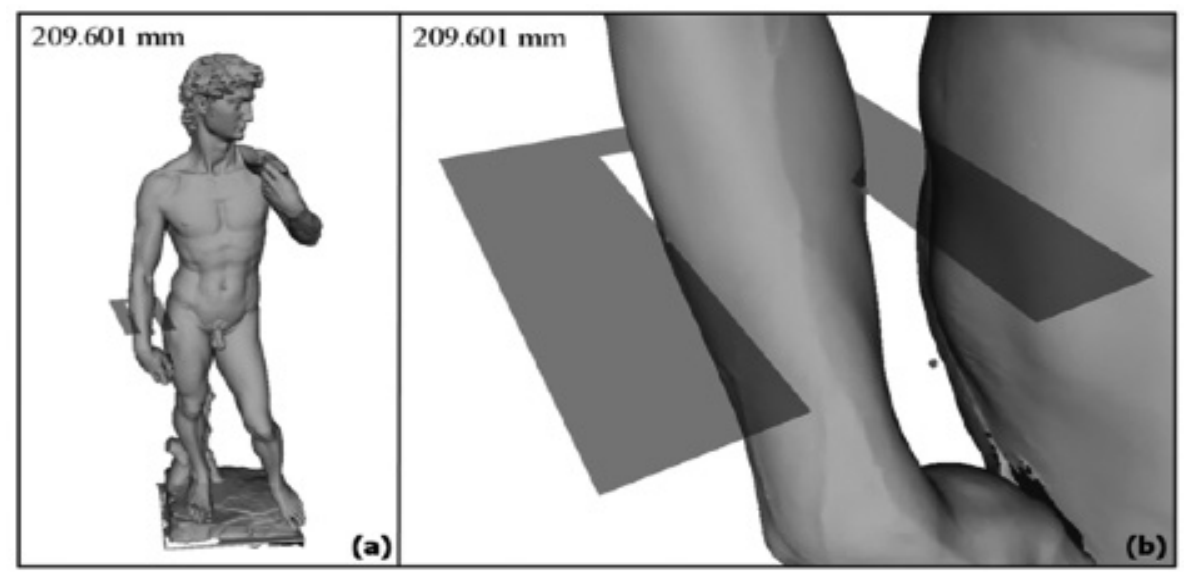

Resim 5 CH Toolbox uygulaması ile mermer bir heykelin kumpas ile yap1lan sanal ortamda ölçümünün görüntüsü (Balcısoy ve Özmen 2008)

Türkiye'deki yeni medya uygulamaları örneklerinden bir başkası ise üç boyutlu canlandırmanın uygulandığı Yalburt Hitit anıtıdır. Kalaycı, Öğütçü ve Karauguz, yakın mesafe fotogrametrik yöntemle üç boyutlu dijital modellemeyi basit ve ekonomik bir yöntem olarak önermektedir (2016) (Resim 5-6). Araştırmacılar anıtın gelecek nesillere aktarılması için dijital ortamda korunmasının önemini vurgulamışlardır. Ancak bu durum, Yalburt anıtının gerçek ortamda fiziksel olarak da korunması gerekliliği gerçeğini değiştirmemektedir. 

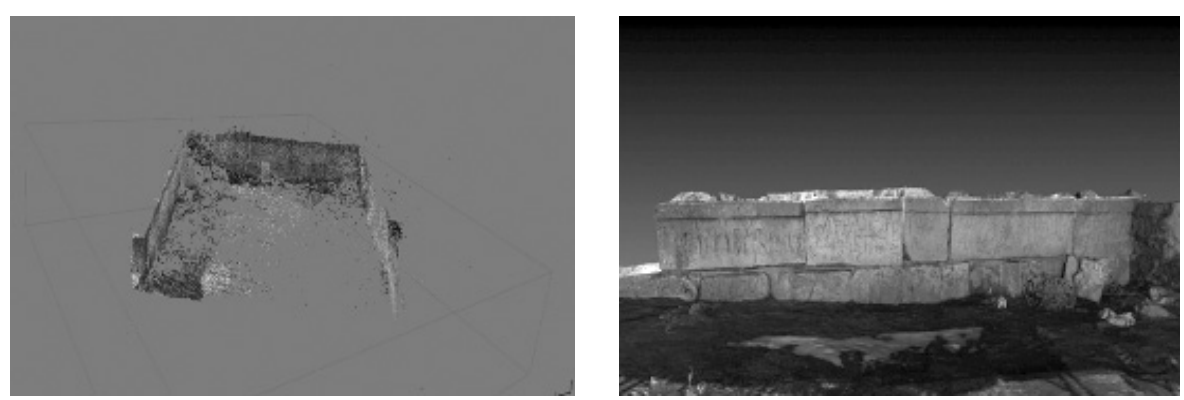

Resim 6 Yalburt anıtı fotogrametrik yöntemle 3 boyutlu modelleme uygulaması (Kalaycı ve Öğütcü, Karauguz 2016: 3-5)

\section{Disiplinlerarası Çalışmalar Bağlamında Yeni Medya Uygulamaları}

Yeni medya ve kültürel miras ilişkisi özetle:

1) Müzede sergilenen eserler için ziyaretçilerin interaktif katılımını ve bilgilenmesini sağlamaya yönelik çalı̧̧malar

2) Arkeolojik sit alanlarının ziyaretçiler tarafından daha iyi algılanmasına yönelik uygulamalar

3) Mimari kalıntıların rekonstrüksiyonu

4) Eğitim alanındaki uygulamalar

5) İnternet üzerinden uzaktan erişim ile ilgili uygulamalar

Başlıklarında toplanabilir. Bu uygulamaların ortak amacının, yeni medya öznesi olan kullanıcının etkin katılımı olduğu görülmektedir. Ortak teknik özellikleri değerlendirdiğimizde ise üç boyutlu yeniden canlandırmaların ve sanal gerçekliğin yoğun olarak kullanıldığı anlaşılmaktadır. Bu tür uygulamalar, McLuhan'ın savunduğu teknoloji ve medya arasında farkın olmadığı (ve bunların insan duyularını bir uzantısı olduğu) şeklindeki kuramla ilişkilidir.

Üç boyutlu canlandırma, rekonstrüksiyon ve sanal gerçeklik uygulamalarında korumayla ilişkili "faraziyenin başladığı yer" ve "tarihi tanıklığ yanlış bir şekilde yansıtmaması" kavramlarının önem kazanmaktadır.

Kültürel mirasın özgülük ölçütü de izleyicinin algısıyla ilişkili olarak önemlidir. Sanal ortam, eserin izleyici tarafından daha iyi anlaşılmasını hedeflerken grafik tasarım mimari yapıyla ilgili özgünlüğü ve ilgili tarihi dönemleri yeteri kadar yansitmayabilmektedir. Bu nedenle yapı kolaylıkla, sanal ortamda oynanan tarihi dönem oyunlarının bir ögesi gibi algılanabilmektedir. 
Yeni medya ortamında kullanıcının, uygulamanın bir parçası haline geldiği ve gerçeklik algısının bulanıklaştığını kabul edersek; bu tür uygulamaların doğru yapılandırılmadığında koruma ve onarımın temel ilkeleri ile çakıştığı rahatlıkla anlaşılmaktadır. Bunun yanı sıra, yeni medyanın kültürel miras uygulamaları, kültürel miras uzmanlarının işbirliğinde yapılmadığında söz konusu ilkelerin farkındalığı bile rahatlıkla sorgulanabilir.

Özmen ve Balcısoy, kültürel miras alanı uzmanlarının geleneksel yöntemlere göre eğitim aldıkları için yeni uygulamaların bu alana uyarlanmasının zor oluğundan bahseder (Özmen ve Balc1soy 2006: 1). Ancak yeni medya uygulamalarının yalnızca teknik uzmanlar tarafından düşünülmesi, yapılandırılması ve geliştirilmesi iki alan arasındaki karşılıklı etkileşimi ve uygulamanın kullanıcı tarafından benimsenmesine engel olabilmektedir. Yine bu şekilde geliştirilen uygulamalar kullanıcıyı yanlı̧ yönlendirebilmektedir.

Arkeolojik ve tarihi yapıların yeniden canlandırılmasını yapan Romanyalı grafik tasarımcı Nemeth'in yakın tarihli çalışması Efes Celsus kütüphanesidir (Res.1).

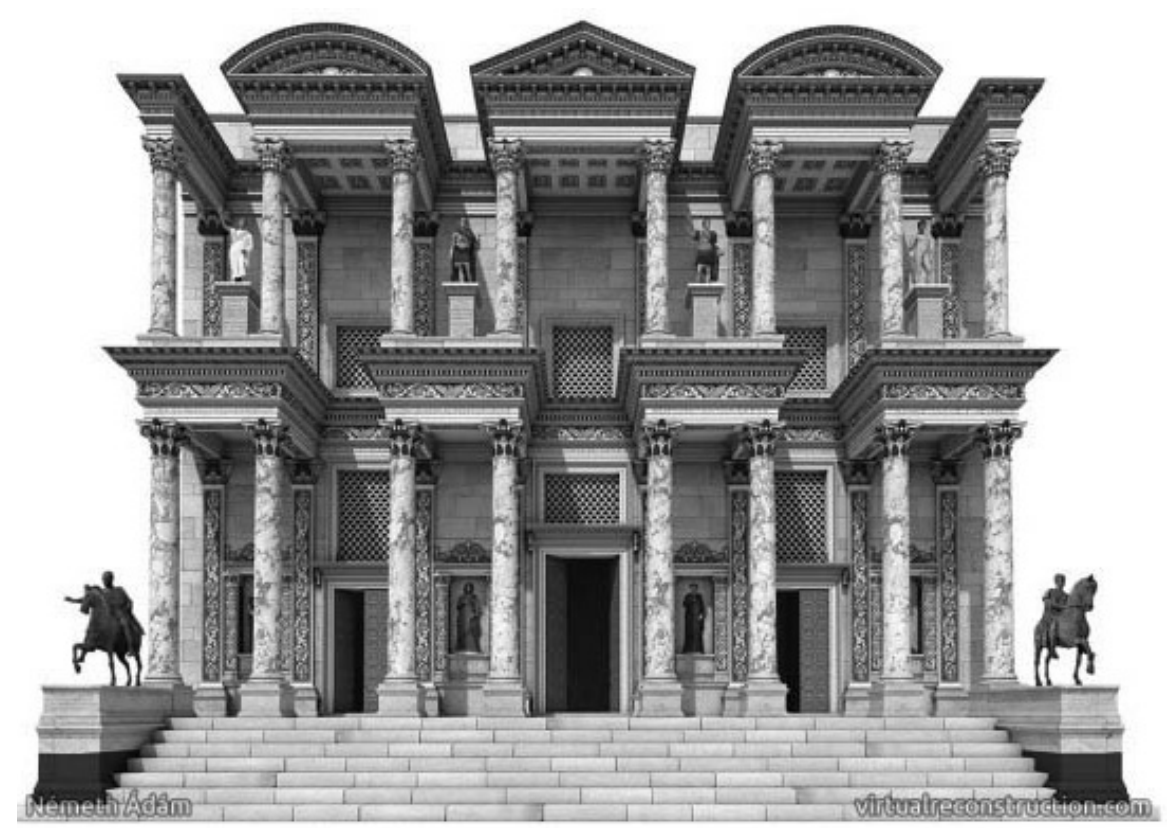

Resim 7 Efes Celsus Kütüphanesi (Nemeth 2016, Erişim tarihi: 9 Ekim 2017, http://virtualreconstruction.com/wp/?p=579) 
Örnekte olduğu gibi tarihi yapıların yeniden canlandırılmasıyla ilgili bir çok uygulamada, kullanılan tarihsel ya da arkeolojik verilerle ilgili bir açıklama bulunmamaktadır. Kullanıcı bu görselin oluşturulmasında yararlanılan bilgiler hakkında bilgi sahibi olmalıdır. Aynı zamanda tamamlamaların hangi bölümlerinin kurguya dayalı olduğu belirtilmelidir.

$\mathrm{Bu}$ nedenle, ilgili disiplinlerin ortak çalışmasıyla çağdaş araçların yeni bir ortam olarak kültürel miras alanında koruma ve interaktif eğitim amacıyla uygulanması sağlanmalıdır. Özellikle, üç boyutlu canlandırma, rekonstrüksiyon ve sanal gerçeklik izleyiciyi kolaylıkla yanlış yönlendirebileceğinden uygulamalar koruma alanıla ilgili uzmanların önerileri doğrultusunda geliştirilmelidir.

\section{SONUÇ}

Yeni medya uygulamalarının kültürel miras alanındaki yansımasını, konunun ana öznesi olan kültürel miras bağlamında üç bileşenli olarak değerlendirmek gerekir: 1. uygulamayı geliştiren uzman; 2. arkeologlar ve kültürel miras ile ilgili tüm uzmanlar; 3. kullanıcı.

Uygulamanın teknik anlamda yapılandırılmasını sağlayacak 1. bileşen olan uzman, altyapıyı 2. bileşen olan arkeologlar ve kültürel miras ile ilgili uzmanların ihtiyaç, istek ve önerileri rehberliğinde oluşturmalıdır. Bu şekilde yeni medya uygulamaları kültürel miras alanında bir amaç ve hedef doğrultusunda anlamlı hale gelebilir. Arkeoloji ve kültürel miras alanı ile ilgili uzmanlar ile alan araştırmacıları ve ziyaretçiler 3. bileşen olan kullanıcıyı tanımlamaktadır. Farklı karakterlerdeki kullanıcıların uygulamayı kullanabilmesi ve kültürel miras unsurlarını özgün olarak algılayabilmesi, farklı disiplinlerin ortak çalışmasıyla mümkün olabilecektir. Uzmanlar, yeni medya uygulamalarının kullanıcı için geleneksel yöntemlere göre maddi, zamansal ve bilimsel anlamda daha tercih edilir olmasını sağlamalıdır.

Yeni medya uygulamaları, en son teknolojik gelişmelerin kültürel miras unsurları için de uygulanması anlamına gelmemektedir. Williams'in savunduğu gibi yeni teknolojiler, var olan sosyal grupların önemli ya da gerekli gördüğü uygulamaları irdeleyerek ileriye taşımalıdır.

Bu nedenle, ilgili uzmanların işbirliğinde özellikle dijital ortamda teknolojik araçlarla oluşturulan kültürel miras konulu uygulamaların, öncelikle amacının iyi belirlenmesi gerekmektedir. Bu amaç da eserlerin özgün değerini kullanıcıya doğru olarak aktarılmasını sağlamakla ilişkilendirilmelidir. Grafik 
tasarım ile görsel olarak yapıları zenginleştiren ve kullanıcının interaktif etkileşimine olanak tanıyan canlandırmaların bilimsel nitelikle olmaları ve bu doğrultuda başarıya ulaşmaları için tarihçilerin, arkeologların, sanat tarihçilerinin ve koruma alanındaki tüm uzmanların görüşleri içermelidir.

Dünyada ve Türkiye'de henüz yeni şekillenmeye başlayan ancak hızla gelişen yeni medyanın kültürel miras alanındaki uygulamaları için kavramsal çerçevenin sağlamlaştırılması ve konuyla ilgili uzmanların işbirliğinin sağlanması ile yeni medya

1. Müzelerde mekan yetersizliği nedeniyle sergilenemeyen eserlerin sergilenebilmesine ve sergide olanların ziyaretçiler için anlaşılabilirliğinin arttırılmas1

2. Arkeolojik sit alanları ya da mimari yapılarda yapilması planlanan maliyeti yüksek rekonstrüksiyonlar için yeni bir alternatif oluşturulması

3. Arkeolojik ve mimari sit alanlarında, ziyaretçilerin kenti daha iyi algılayabilmesine yardımcı bir araç sağlanması alanlarında daha etkin ve doğru olarak kullanılabilecektir.

Bunun yanı sıra, günümüzde çok farklı alanlarda kullanılan zenginleştirilmiş gerçeklik teknolojilerinin, kültürel mirasın kullanıcı açısından fayda ilişkisi bağlamında uygulanabilirliği en yüksek yeni medya aracı olduğu söylenebilir. Son yılların en önemli eğitsel teknolojilerden biri olarak gösterilen zenginleştirilmiş gerçeklik, kullanıcının kendisini çevreleyen ortamda gerçek zamandaki algısını arttırmak ve kullanıcıyı interaktif hale getirmek için bilgisayar aracıllğıyla üretilmiş sanal bilgiyi ve görüntüleri gerçek ortamla üst üste getiren bir teknolojidir ve bu nedenle kültürel miras alanında amaca yönelik olarak uygulanabilirliği yüksektir.

Ayrıca, bugün bazı tanımlara göre eski medya ortamları olarak kabul edebileceğimiz fotoğraf ve resim medyalarının da dijital değerlere dönüştürülerek geleneksel analog yöntemler ve dijital ortamın kullanıldığı melez metotlarla, kültürel miras alanında uygulanabileceği olasılıkları değerlendirmek gereklidir.

Bu doğrultuda düzenlenecek panel, sempozyum ve kongrelerde yeni medya teknolojileri için güncel sorunlar saptanarak olası çözüm önerileri oluşturulması; ortak ilkeler ve yöntemler belirlenmesi gerekmektedir. 


\section{Kaynaklar}

Aktaş, Celalattin (2007). "Yeni Medyanın Geleneksel Medya ile Karşılaştırrlması”, Ed. Gülbuğ Erol, Medya Üzerine Çalısmalar, İstanbul: Beta Yayınları, s.84-98.

Akyazı, Ayşenur (2014). "Yeni İletişim Ortamı Olarak Dijital Katılımcı Sözlüklerde Nefret Söylemi”, Marmara İletişim Dergisi 22(1), s.183-194.

Courtney, Rosemary (1986). Longman Dictionary of Phrasal Verbs, Harlow, Essex: Longman.

Damaiano, Rossana ve Vincenzo Lombardo, Antonio Lieto, Davide Borra (2016). "Exploring Cultural Heritage Repositories with Creative Intelligence. The Labyrinth 3D System”, Entertainment Computing 16, s. $41-52$.

Holzmann, Steven (1997). Digital Mosaics: The Aesthetics of Cyberspace, New York: Simon and Schuster.

Kalay, Yehuda (2008). "Introduction: Preserving Cultural Heritage Through Digital Media”, Ed. Yehuda Kalay, Thomas Kvan, Janice Affleck, Nerw Heritage, New Media and Cultural Heritage, London and New York: Routledge, s. 1-10.

Kalaycı, İbrahim ve Sermet Öğütcü, Güngör Karauguz (2016). “3D Model of Hittite Yalburt Monument", IOP Conf. Series: Earth and Environmental Science 44 (032009).

Kaplan, Kenan ve Elif Ertürk (2012). "Dijital Çağ ve Bireyin İdeolojik Aygitları", The Turkish Online Journal of Design, Art and Communication 2 (4), s.7-12.

Khan, Muqeem ve Penny de Byl (2011). "Preserving Our Past with Toys of the Future”, ed. G. Williams, P. Statham, N. Brown, B. Cleland, Ascilite 2011 Changing Demands, Changing Directions, Tasmania: University of Tasmania.

Liritzis, I. ve F.M. Al-Otaibi, P. Volonakis, A. Drivaliari (2015). "Digital Technologies and Trends in Cultural Heritage", Mediterranean Archaeology and Archaeometry 15(3), s.313-332.

Lister, Martin ve Jon Dovey, Seth Giddings, Ian Grant, Kieran Kelly (2009). New Media: A Critical Introduction, London and New York: Routledge.

Manovich, Lev (2001). The Language of New Media, Cambridge: MIT Press.

Mcluhan, Marshall (1964) Understanding Media: The Extensions of Man, New York: McGraw-Hill. 
Mcluhan, Marshall ve Quentin Fiore (1967). The Medium is The Massage, London: Penguin Books.

Mcluhan, Marshall ve Quentin Fiore (1968). War and Peace in Global Village, New York: Bantam Books.

Mcluhan, Marshall (2014). Gutenberg Galaksisi: Tipografik İnsanın Oluşumu, İstanbul: Yap1 Kredi Yayınları.

Nemeth Adam (Eylül 2016). "Adam Nemeth's Virtual Reconstructions", (Erişim tarihi: 9 Ekim 2017), http://virtualreconstruction.com/ $\mathrm{wp} / \mathrm{p}=579$.

Odabaş, Osman (2016). "Yeni bir Karışık Teknik: Dijital Tasarım ve Geleneksel Yüzey”, Made by Artist I. International Art and Design Symposium, İstanbul: İkinciadam Yayınları, s.463-472.

Özmen, Can ve Selim Balcısoy (2006). "A Framework for Working with Digitized Cultural Heritage Artefacts”, ISCIS'06, Lecture Notes in Computer Science, 4263, s.394-400.

Özmen, Can ve Selim Balcisoy (2008). “Bimanual Interactive Tools for Cultural Heritage Researchers", Proceedings of the International Conference on Cyberworlds 2008, Hangzhou, China, 22-24, s.439-446.

Poster, Mark (1995). The Mode of Information, Cambridge: Polity Press.

Poster, Mark (1999). "Underdetermination”, New Media and Society 1(1), s.12-17.

Rheingold, Howard (1991). Virtual Worlds, London: Secker and Warburg.

Robins, Kevin (1996) Into the Images: Culture and Politics in the Field of Vision, London and New York: Routledge.

Şahin, Serpil (2015). “Dijital Çağ ve Sanatta Yaptığı Dönüşümler”, Görünüm $1(1)$, s.38-50.

Themistocleous, Kyriacos (2016). "Model Reconstruction for 3D Vizualization of Cultural Heritage Sites Using Open Data from Social Media: The Case Study of Soli, Cyprus", Journal of Archaeological Sciences 14(4) s.774-781.

Türk Dil Kurumu (2017). Büyük Türkçe Sözlük, (Erişim tarihi: 9 Ekim 2017), http://www.tdk.gov.tr/index.php?option=com_bts.

Wands, Bruce (2006) Art of The Digital Age, London: Thames \& Hudson.

Weibel, P. (1996). “The World as Interface”, ed. Timothy Druckrey, Electronic Culture, New York: Aperture. 
Williams, Raymond (1974). Television, Technology and Cultural Form, London: Fontana Communications Series.

Williams, Raymond (1976). Keywords: A Vocabulary of Culture and Society, London: Fontana Communications Series.

Yaylagül, Levent (2010). Kitle İletişim Kuramlar, Ankara: Dipnot Yayınevi.

Youngblood, Gene (1999). "A Medium Matures: Video and the Cinematic Enterprise”, ed. T. Druckrey, Ars Electronica Facing the Future, Cambridge: MIT Press. 


\section{ABSTRACT \\ New Media Applications on Cultural Heritage Assets}

New media is a relatively new concept for cultural heritage field. New media is usually considered the same as digital media and technology-driven alternatives. A better understanding of new media concept especially for cultural heritage studies could provide limitless possibilities for preserving, monitoring, representation and management of cultural assets. Using digital techniques make it possible to build 3D models, reconstructions, environments of virtual reality of archaeological sites or ancient structures and related cyber games. However, the nature of the object that is "cultural heritage components" of such applications requires collaboration with experts and academics, which specialize in the field of cultural heritage studies. Since, if the applications are not formed involving preservation and conservation principles, users/subjects of these applications could be easily manipulated and misdirected. Therefore, a conceptual context of new media applications for cultural heritage sites should be created. In this study, the very fundamentals of new media concept were analyzed and the latest trends in new media applications for archaeological sites and structures were determined in order to suggest an appropriate way of understanding such studies for cultural heritage area. It is concluded that nearly all of the latest applications and general scientific approach involves the view merely from the point of technological side.

Keywords: New Media, Digital Media, Cultural Heritage, Reconstruction, Virtual Reality, Augmented Reality 